\title{
CONFIGURATION AND SPECIFICATIONS OF AN UNMANNED AERIAL VEHICLE FOR PRECISION AGRICULTURE
}

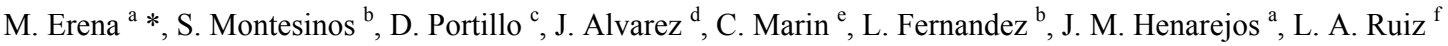 \\ ${ }^{a}$ GIS and Remote Sensing Group- IMIDA, 30150. La Alberca. Murcia. Spain - manuel.erena@carm.es \\ ${ }^{\mathrm{b}}$ SM Geodim, Torre Albarrana. 50340 Maluenda. Zaragoza. Spain - smontesinos@geodim.es \\ ${ }^{\mathrm{c}}$ Habitat, Avda. Don Juan de Borbón, No 98, C.P. 30007, Murcia, Spain - d.portillo@habitatea.es \\ ${ }^{\mathrm{d}}$ Droning, Calle Astronomía 1, Torre 2,6-11.41015. Sevilla, Spain - j.alvarez@droning.es \\ e Bioiberica, Plaça Francesc Macià, 7. 08029. Barcelona, España - cmarin@bioiberica.com \\ ${ }^{\mathrm{f}}$ Geo-Environmental Cartography \& Remote Sensing Group, UPV, Calle Vera s/n, 46022. Valencia, Spain - laruiz@cgf.upv.es
}

Commission I, ICWG I/Vb

KEY WORDS: UAV, calibration, multispectral, multitemporal, viticulture

\begin{abstract}
:
Unmanned Aerial Vehicles (UAVs) with multispectral sensors are increasingly attractive in geosciences for data capture and map updating at high spatial and temporal resolutions. These autonomously-flying systems can be equipped with different sensors, such as a six-band multispectral camera (Tetracam mini-MCA-6), GPS Ublox M8N, and MEMS gyroscopes, and miniaturized sensor systems for navigation, positioning, and mapping purposes. These systems can be used for data collection in precision viticulture. In this study, the efficiency of a light UAV system for data collection, processing, and map updating in small areas is evaluated, generating correlations between classification maps derived from remote sensing and production maps. Based on the comparison of the indices derived from UAVs incorporating infrared sensors with those obtained by satellites (Sentinel 2A and Landsat 8), UAVs show promise for the characterization of vineyard plots with high spatial variability, despite the low vegetative coverage of these crops. Consequently, a procedure for zoning map production based on UAV/UV images could provide important information for farmers.
\end{abstract}

\section{INTRODUCTION}

In the domain of precision farming, the contemporary generation of aerial images with high spatial resolution is of great interest. Useful in particular are aerial images in the thermal (TIRS) infrared (Suarez et al., 2010) and near-infrared (NIR) spectrum (Nebiker et al., 2008). Unmanned Aerial Vehicles (UAVs) with multispectral sensors are becoming increasingly attractive in viticulture for data capture and map updating at high spatial and temporal resolutions. These systems can be used for data collection in precision viticulture (Arno, 2008), (Bellvert, 2014) and (Montesinos, 2015).

Airborne thermal and multispectral images have also been applied successfully to the detection of water stress at larger scales. Normalized canopy temperature, chlorophyll content, and photochemical reflectance indices were demonstrated to be the best indicators of early and advanced water stress.

Canopy temperature: Remote sensing of crop temperature was proposed (Tanner, 1963) through the use of thermal infrared sensors. The temperature was a valuable index for the determination of water regimes as well for estimating crop production. Subsequently, the temperature was used as an index for crop water status, relating it to the productivity and water requirements of the plants (Jackson, Reginato, \& Idso, 1977). The "temperature" parameter provided by UAV/aircraft flight allows detection of crop areas with higher temperatures, relating this to their water status. Validation in crops with different water supplies has demonstrated the relationship between temperature and water potential and stomatal conductance, thus showing the feasibility of the detection of areas with water stress by UAV images taken with thermal cameras (Suarez et al., 2010) and (Bellvert, 2014).

Chlorophyll content: Estimation by remote sensing of the chlorophyll content in vegetation has proven to be of great interest because it is an indicator of stress directly related to photosynthetic processes as well as an indicator of nutritional deficiencies. Spectroscopic methods at the leaf and canopy levels allow estimation of the chlorophyll content based on the reflected radiation in the spectral regions of green $(550 \mathrm{~nm})$ and red edge (690-750 nm) (Suarez et al., 2010), therefore allowing the detection of chlorosis in vegetation. The chlorophyll content, in addition to other biochemical constituents such as water content or dry matter, can be estimated using remote sensors installed on the UAV.

TCARI index: The TCARI index (Berni et al., 2009) is one of the products generated after an airborne flight over the vineyard: the spatial variability of the nutritional status indicator is obtained by means of the demonstrated relationship between the chlorophyll content and leaf nitrogen.

PRI: The Photochemical Reflectance Index (Gamon et al., 1992) is an indicator of stress related to fruit quality, due to its relationship with plant photosynthesis. The PRI has been used as a pre-visual indicator of water stress at the leaf scale (Thenot et al., 2010) and canopy scale (Dobrowski et al., 2005). The PRI is calculated to obtain the average per plant of that index. Its association with photosynthesis provides good relationships between the index and fruit quality parameters such as the sugar/acid ratio in the grapes of the vineyard (Suarez et al., 2008) 
This article presents a multiscale approach to obtain different vegetative parameters. Characterization of the spatial variability in water status across vineyards is a prerequisite for precision irrigation. In this paper we used simultaneous UAV and aircraft surveys and Landsat 8 and sentinel II satellite images, acquired over vineyards in southeast of Spain, to assess the capability of each system to represent the intra-vineyard vegetation patterns, to evaluate the similarities of images taken at different spatial resolutions, and to perform an evaluation that combines operational and economic factors. The final outcome of this assessment is the development of a logical framework with the aim of providing guidelines for the choice of the appropriate detection platform as a function of the scale of analysis in precision viticulture. The efficiency of a UAV system for data collection, processing, and map updating in small areas is evaluated, using different indices like enhanced normalized difference vegetation ENDVI (Matsushita et al., 2007).

The investigation was based on a set of aerial images recorded during the flights performed with a UAV system over a commercial vineyard plot in Jumilla and an experimental vineyard in Bullas (Murcia, Spain). Additionally, biophysical indices obtained with the UAV were compared with those obtained by processing Landsat 8 and Sentinel $2 \mathrm{~A}$ images and using multispectral and thermal cameras on-board an airplane. These tests show the preliminary results for the configuration of a UAV-based system to be used for practical applications in precision agriculture (Pierce, 1999), (Reuter and Kersebaum, 2009), (Matese, 2013), (Bellvert et al., 2014) and (Matese \& Di Gennaro, 2015).

\section{MATERIALS}

\subsection{Study Site}

Two vineyards, hereafter referred to as V1 $\left(38^{\circ} 34^{\prime} 05^{\prime \prime} \mathrm{N}\right.$, $\left.1^{\circ} 21^{\prime} 14^{\prime \prime} \mathrm{E}\right)$ and V2 $\left(38^{\circ} 06^{\prime} 39^{\prime \prime} \mathrm{N}, 1^{\circ} 40^{\prime} 59^{\prime \prime} \mathrm{E}\right)$, were chosen as test sites in the Murcia Region (Spain). The vineyards have similar agronomic characteristics. A Monastrel (Vitis vinifera L.) vine is trained to a free cordon with a single horizontal wire $1.5 \mathrm{~m}$ high. Vines spacing is $2.5 \times 1.3 \mathrm{~m}$ between rows and plants, respectively, while the row orientation is Northeast (V1) or Northwest (V2) with flat topography. The climatic characterization used the data collected by the agrometeorological station JU12 $\left(38^{\circ} 02^{\prime} 38^{\prime \prime} \mathrm{N}, 1^{\circ} 58^{\prime} 46^{\prime \prime} \mathrm{E}\right)$. The study was performed in summer 2015, one of the warmest of the period 2000-2015, with annual mean temperatures $17.08^{\circ} \mathrm{C}$, a cumulative rainfall of $349 \mathrm{~mm}$, and an annual evapotranspiration (ETo) of $1377 \mathrm{~mm}$ (Figures 1 and 2).

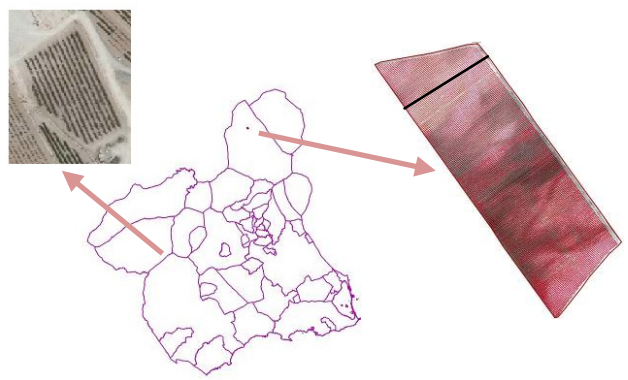

Figure 1 Situation maps of vineyard plots.

The commercial vineyard plot is divided into four zones, according to their lithology and the age of the plantation on the plot. It has a clay soil with low organic matter content (about $1.5 \%$ ), an active silt content of $20 \%$, and a pH of 7.6 .

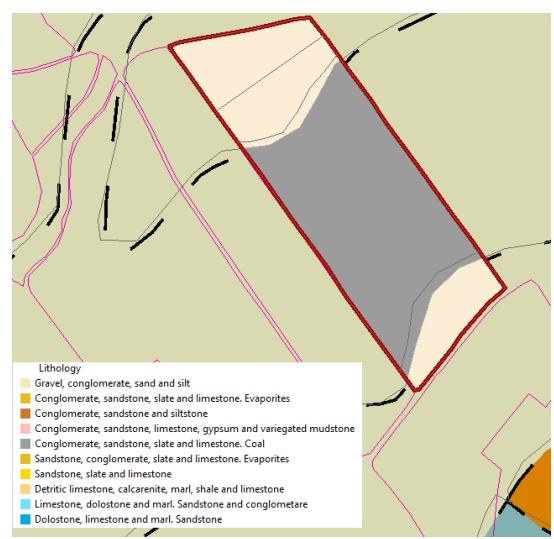

Figure 2 Lithology from the Geological Map of Spain-IGME.

The $V$. vinifera varieties studied were Monastrell, Merlot, and Syrah. The hours and days of the UAV flight and the acquisition of $\mathrm{AV}, \mathrm{L8}$, and Sentinel II images are shown in Figure 3.

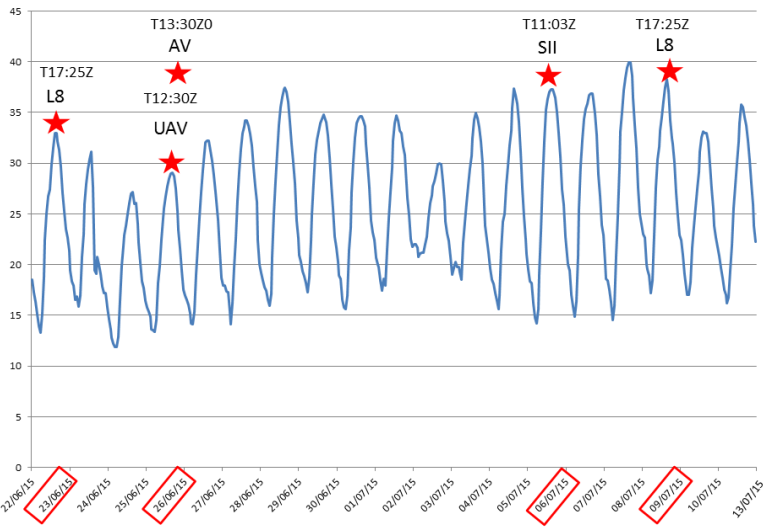

Figure 3. Average hourly temperature at the JU12 station and acquisition dates of the images.

\subsection{UAVs system description}

Two different models of UAV were used: in the commercial vineyard (V1) the Droning D650 UAV (Figure 3) was used and in the experimental vineyard (V2) the Droning D820 UAV (Figure 7) was used.

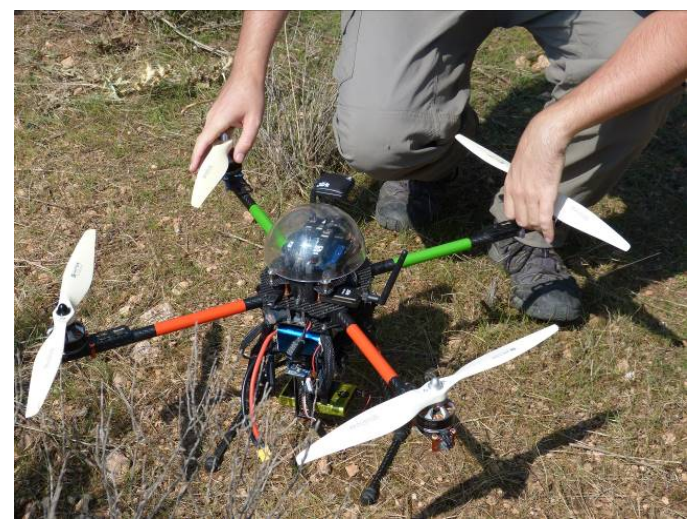

Figure 4. Droning D650 UAV-Canon IXUS 125 HS.

The Droning D650 UAV can carry any sensor weighing less than $0.5 \mathrm{~kg}$, although the maximum recommended payload is $0.30 \mathrm{~kg}$. Two sensors with different spectral and spatial resolutions were mounted on the UAV to be tested separately in 
this experiment: a stationary point-and-shoot camera, model Canon IXUS 125 HS. The Canon camera acquires 16.1 megapixel images (Infrared, IR; Green, G; and Blue, B, bands) with 8-bit radiometric resolution and is equipped with a 4.3 $21.5 \mathrm{~mm}$ zoom lens.

\subsection{Aircraft description}

The aerial images were collected on June $26^{\text {th }} 2015$, T13:30Z to T13:55Z, using a six-band multispectral camera (model Tetracam mini-MCA-6) and FLIR thermal cameras on-board an airplane. The calculated indices are: canopy temperature, NDVI, TCARI, and PRI (Suarez et al., 2008).

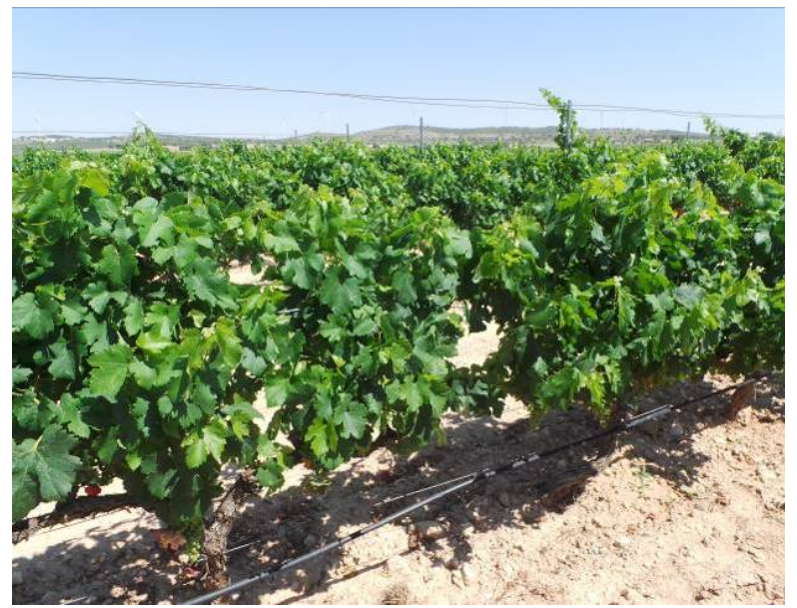

Figure 5. Commercial vineyard plot 2015/06/26T1300Z

\subsection{Satellite description}

Two types of satellite image have been used: Sentinel $\mathbf{2 A}$ is a European wide-swath, high-resolution, multi-spectral imaging mission. The full mission specification of the twin satellites, flying in the same orbit but phased at $180^{\circ}$, is designed to give a high revisit frequency of 5 days at the Equator (ESA, 2015).

Sentinel 2A has an optical instrument payload that samples 13 spectral bands: four bands at $10 \mathrm{~m}$, six bands at $20 \mathrm{~m}$, and three bands at $60 \mathrm{~m}$ spatial resolution. The orbital swath width is 290 $\mathrm{km}$.

$\begin{array}{lccc}\text { Spectral Band; Wavelength }(\mu \mathrm{m}) \text {; Band width }(\mu \mathrm{m}) \text {; Resolution }(\mathrm{m}) \\ \text { B1 } & 0.443 & 0.020 & 60 \\ \text { B2 Blue } & 0.490 & 0.065 & 10 \\ \text { B3 Green } & 0.560 & 0.035 & 10 \\ \text { B4 Red } & 0.665 & 0.030 & 10 \\ \text { B5 } & 0.705 & 0.015 & 20 \\ \text { B6 } & 0.740 & 0.015 & 20 \\ \text { B7 } & 0.783 & 0.020 & 20 \\ \text { B8 NIR } & 0.842 & 0.115 & 10 \\ \text { B8a } & 0.865 & 0.020 & 20 \\ \text { B9 } & 0.945 & 0.020 & 60 \\ \text { B10 } & 1.380 & 0.030 & 60 \\ \text { B11 } & 1.610 & 0.090 & 20 \\ \text { B12 } & 2.190 & 0.180 & 20\end{array}$

Table 1: Spectral bands of SENTINEL-2 MSI

The Level-1C product provides orthorectified Top-OfAtmosphere (TOA) reflectance values, with sub-pixel multispectral registration.

The aerial images were collected on July $6^{\text {th }} 2015$, at T11:03Z, using the spectral band numbers $2,3,4$, and $8(10 \mathrm{~m})$ of the MSI sensor.
Landsat 8: Landsat 8 products provided by the USGS EROS Center consist of quantized and calibrated, scaled Digital Numbers (DN) representing multispectral image data acquired by both the Operational Land Imager (OLI) and Thermal Infrared Sensor (TIRS). The products are delivered in 16-bit unsigned integer format and can be rescaled to the Top Of Atmosphere (TOA) reflectance and/or radiance using radiometric rescaling coefficients provided in the product metadata file. The MTL file contains the thermal constants needed to convert TIRS data to the at-satellite brightness temperature. Landsat 8 satellite images cover Earth every 16 days. Landsat 8 data products are consistent with the all standard Level-1 specifications: OLI multispectral bands 1-7, 9: 30-meters; OLI panchromatic band 8: 15-meters; TIRS bands 10-11: 100 meters; Orthorectified; 16-bit pixel value. (USGS, 2015).

$\begin{array}{llc}\text { Spectral B } & \text { Wavelength }(\mu \mathrm{m}) & \text { Resolution }(\mathrm{m}) \\ \text { B1 - Aero. } & 0.433-0.453 & 30 \\ \text { B2 - Blue } & 0.450-0.515 & 30 \\ \text { B3 - Green } & 0.525-0.600 & 30 \\ \text { B4 - Red } & 0.630-0.680 & 30 \\ \text { B5 - NIR } & 0.845-0.885 & 30 \\ \text { B6 - IR } & 1.560-1.660 & 30 \\ \text { B7 - IR } & 2.100-2.300 & 30 \\ \text { B 8 - Pan } & 0.500-0.680 & 15 \\ \text { B 9 - Cirrus } & 1.360-1.390 & 30 \\ \text { B10 - LI } & 10.30-11.30 & 100 \\ \text { B11 - LI } & 11.50-12.50 & 100\end{array}$

Table 2. Spectral bands of Landsat 8 (OLI/TIRS)

\section{METHODS}

\subsection{UAV image acquisition}

The set of aerial images was collected on June $26^{\text {th }} 2015$, T12:00Z - T13:30Z (Figure 6), with a stationary point-andshoot camera (Canon, model IXUS 125HS). The index obtained was ENDVI (Figure 9).

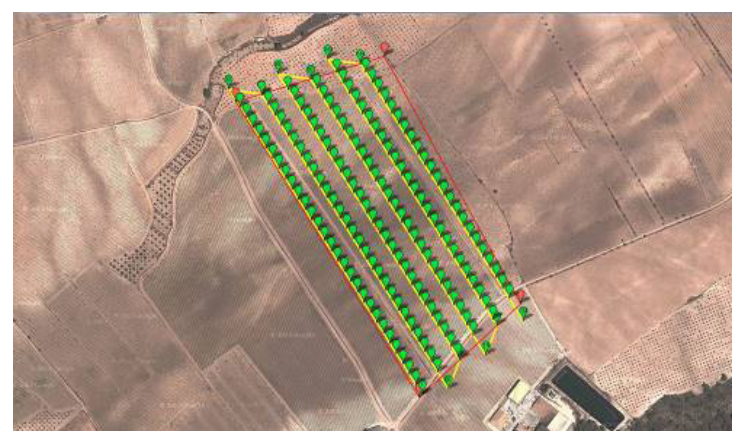

Figure 6. Flight plan of the vineyard plot 2015/06/26T1300Z (0.1m)

A sequence of images was collected in each flight mission to cover the whole commercial crop field.

An important task prior to image analysis was the combination of all these individual and overlapped images by applying two consecutive processes of orthorectification and mosaicking. Agisoft Photoscan Professional Edition (Agisoft, 2016) software was employed in this task, together with the information related to the roll, pitch, and yaw of the vehicle in each acquired image. Then, the orthorectification and mosaicking of the imagery set into a single image of the whole experimental field was performed. 
The Droning D820 UAV can carry any sensor weighing less than $1.5 \mathrm{~kg}$, although the maximum recommended payload is $0.80 \mathrm{~kg}$. Two sensors with different spectral and spatial resolutions were mounted on the UAV to be tested separately in this experiment: a stationary point-and-shoot mirrorless camera, model Sony QX1 with a Rosco \#2007 VS Blue filter, and a sixband multispectral camera, model Tetracam mini-MCA-6.

The Sony camera acquires 20.1-megapixel images (Infrared, IR; Green, G; and Blue, B, bands) with 8-bit radiometric resolution and is equipped with a $16-50 \mathrm{~mm}$ zoom lens. The Rosco \#2007 filter allows much blue light $(0.4-0.5 \mu \mathrm{m})$ and much near infrared light $(>0.7 \mu \mathrm{m})$ to pass, but very little red light $(0.6$ $0,7 \mu \mathrm{m})$ (Public Lab, 2016)

The Tetracam mini-MCA-6 (Tetracam, 2016) is a lightweight $(700 \mathrm{~g})$ multispectral sensor composed of six individual digital channels arranged in a $2 \times 3$ array. The images can be acquired with 10-bit radiometric resolution. The camera has user configurable band pass filters of $10-\mathrm{nm}$ full-width at halfmaximum and center wavelengths at $\mathrm{B}(0.49 \mu \mathrm{m}), \mathrm{G}(0.55 \mu \mathrm{m})$, $\mathrm{R}(0.68 \mu \mathrm{m}), \mathrm{R}$ edge $(0.72 \mu \mathrm{m})$, and near-infrared (NIR, 0.80 $\mu \mathrm{m}$ NIR, $0.90 \mu \mathrm{m})$. These bandwidth filters were selected across the visible and NIR regions, considering well-known biophysical indices developed for vegetation monitoring. Image triggering is activated by the UAV according to the programmed flight route. At the moment of each shoot, the onboard computer system records a timestamp, the GPS location, the flight altitude, and the vehicle principal axes. The flight time was restricted to approx. 30-45 min in our conditions of use (altitude $120 \mathrm{~m}$, payload $700 \mathrm{~g}$, battery capacity 22000 $\mathrm{mAh}$ ) (Figure 7).

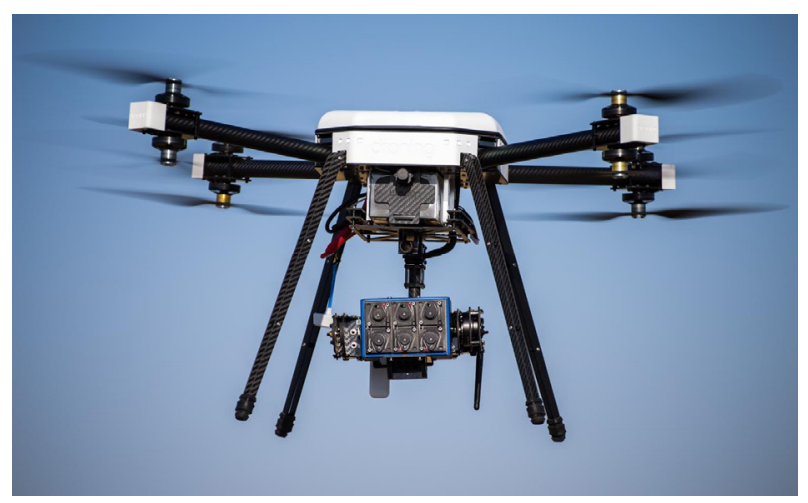

Figure 7. Droning D820 UAV with Tetracam mini-MCA-6

The Tetracam PixelWrench 2 (PW2) software (Tetracam, 2016), supplied with the multispectral camera, was used to perform the alignment process. The PW2 software provides a band-to-band registration file that contains information about the translation, rotation, and scaling between the master and slave channels.

Another interesting sensor to increase the functionality of the UAV is the FLIR Tau ${ }^{\circledR} 2$ thermal imaging camera, which includes radiometry, increased sensitivity $(<30 \mathrm{mK})$, and $640 / 60 \mathrm{~Hz}$ frame rates (Flir, 2016).

\subsection{Aircraft image acquisition}

The flight with the plane was performed with sensors, a 6-band multispectral imager (Tetracam, model mini-MCA), and a thermal camera (FLIR model TAU) mounted on a Cessna 150 aerobat aircraft, flying at $200 \mathrm{~m}$ above ground level for a resolution of $50 \mathrm{~cm}$. Date: 2015/06/26T1330Z.

All images were then processed with QGIS software (Quantum GIS Development Team (2.8.6)). Quantum GIS Geographic Information System. Open Source Geospatial Foundation Project. http://qgis.osgeo.org/es/site/.

\subsection{Satellite image processing}

The automatic IMIDA processing system generates agrometeorological products from Landsat 8 . These images were downloaded by http and stored in a directory; the products are automatically detected and are inserted in the products archive.

The sensor network registers the air temperature observations each hour; these data are collected and stored by the automatic system of Fig. 8.

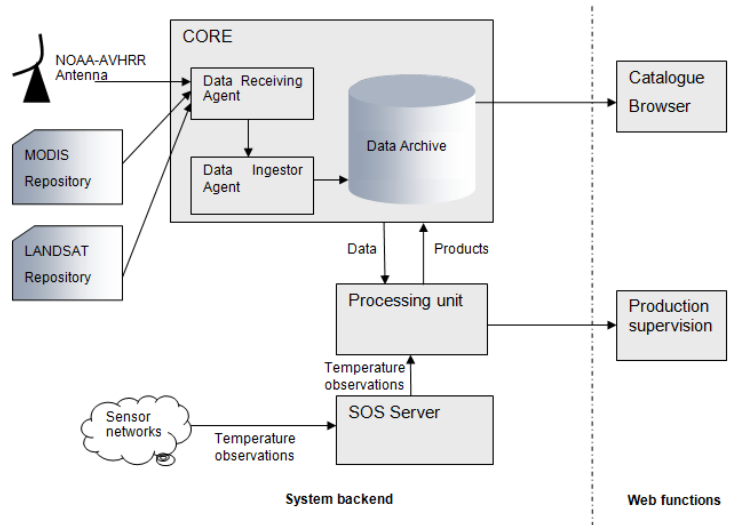

Figure 8 . An automatic image processing system

Each Landsat 8 image received is processed to generate the following products covering Murcia: Radiance, Reflectance, NDVI, Land Surface Temperature -LST (B10 and B11), Soiladjusted vegetation index-SAVI, Leaf Area Index-LAI, and Air Temperature $-\mathrm{AT}$.

The system makes use of OGC standard web services: the SOS (Sensor Observation Service) is used to store and make available the in-situ data observations. It is responsible for collecting the observations from the sensor network. It is foreseen that this implementation will be based on SOS $52^{\circ}$ North (Erena et al., 2015).

Further details can be found in the LDCM Cal/Val algorithm description document and the Landsat 8 Science Users' Handbook available from the Landsat website (USGS, 2015), (Chander et al., 2009), and (Ariza, 2013).

The description of the processing system and products is available on the website http://idearm.imida.es/. (Erena, M., \& García, S., 2014)

Three indices were used in this study:

The Normalized Difference Vegetation Index (NDVI), proposed by (Rouse, 1972), is one of the most widely used vegetation indices. It is based on the distinctive radiometric behavior of vegetation throughout certain spectral windows. Healthy vegetation shows a characteristic spectral signature with a clear contrast between the visible bands, especially the 
red band $(0.630-0.680 \mu \mathrm{m})$ and near-infrared $(0.845-0.885$ $\mu \mathrm{m})$. This marked difference between the absorption spectra in the visible and near-infrared (NIR) of healthy vegetation allows it to be distinguished from vegetation suffering some kind of stress (water stress, for example, caused by drought), in which there is less reflectance in the NIR and greater absorption in the visible. The NDVI is calculated using the expression proposed by (Rouse, 1972):

$$
N D V I=\frac{\rho_{\text {NIR }}-\rho_{\text {red }}}{\rho_{\text {NIR }}+\rho_{\text {red }}}
$$

The Soil-Adjusted Vegetation Index - SAVI (Huete, 1988) is calculated by the expression:

$$
S A V I=\frac{N I R-R E D}{(N I R+R E D+L)} *(1+\mathrm{L})
$$

Where NIR is the reflectance value of the near infrared band, RED is the reflectance of the red band, and L is the soil brightness correction factor. The value of $L$ varies according to the amount or cover of green vegetation: in regions with a very dense vegetation cover, $\mathrm{L}=0$; and in areas with no green vegetation, $\mathrm{L}=1$.

ENDVI is calculated using the expression:

$$
E N D V I=\frac{\left(\rho_{\text {NIR }}-\rho_{\text {green }}\right)-\left(2 \times \rho_{\text {blue }}\right)}{\left(\rho_{\text {NIR }}+\rho_{\text {green }}\right)+\left(2 \times \rho_{\text {blue }}\right)}(3)
$$

Where $\rho=$ reflectance in the corresponding band.

\section{RESULTS}

\subsection{UAV}

This paper first presents a camera system designed for georeferenced NIR orthophoto generation, which was reliably used on a UAV (Figure 9). Although the orthophotos seemed to be self-consistent, we carried out a ground control measurement with GNSS to examine the relative and absolute accuracy.

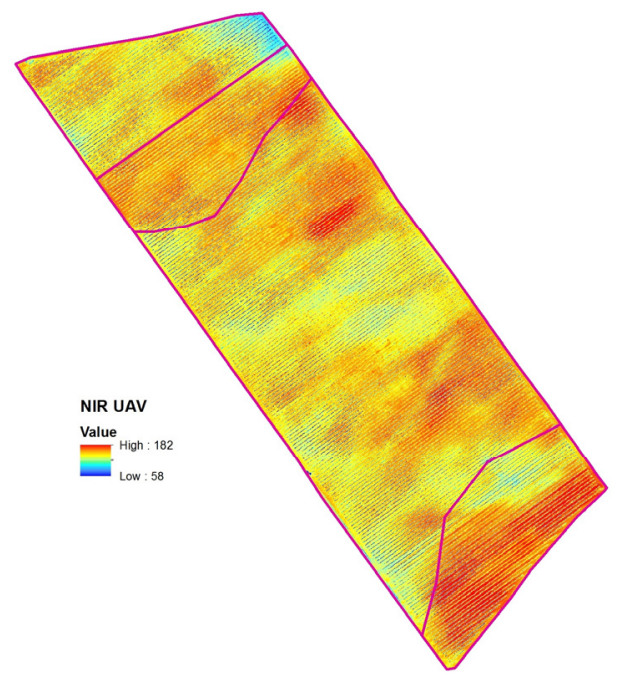

Figure 9. ENDVI 2015/06/26T1300Z (0.1m)

\subsection{Aircraft}

The results obtained with the thermal camera highlight the great differences in water stress among the different plots of the farm, which condition the production - in terms of quantity and quality - of the vineyard (Figures 10, 11, and 12).

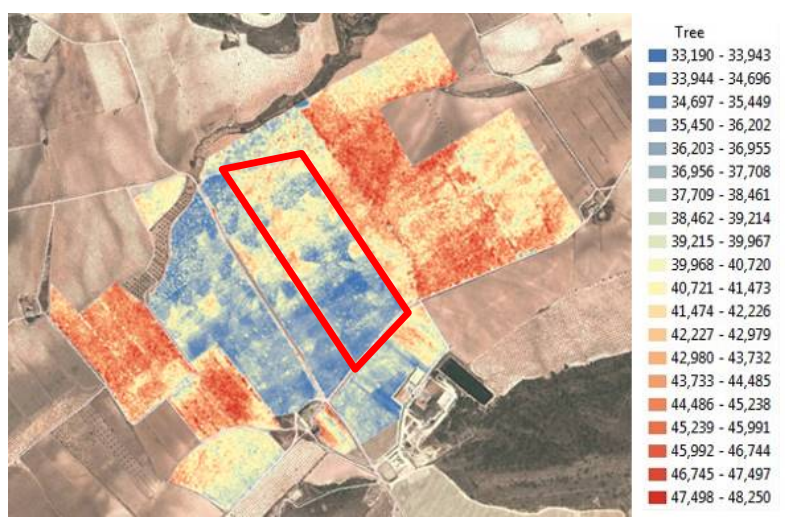

Figure 10. Canopy temperature $\left({ }^{\circ} \mathrm{C}\right) 2015 / 06 / 26 \mathrm{~T} 1330 \mathrm{Z}(0.5 \mathrm{~m})$

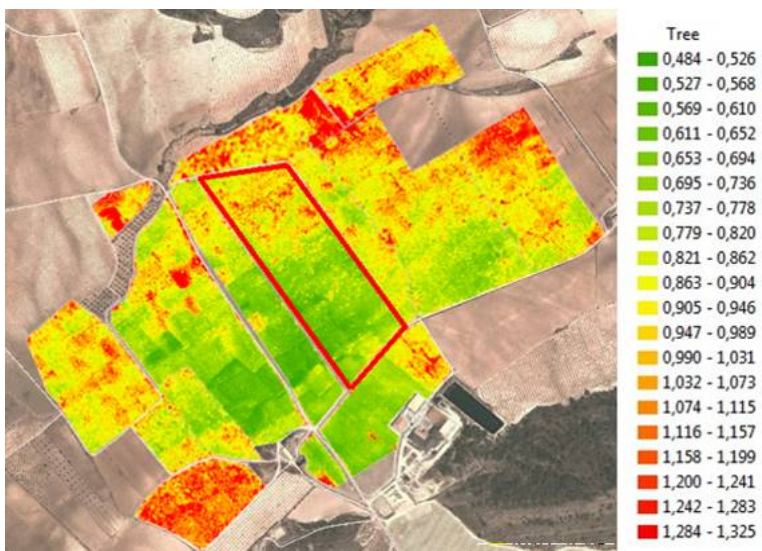

Figure 11. TCARI index 2015/06/26T1330Z (0.5m)

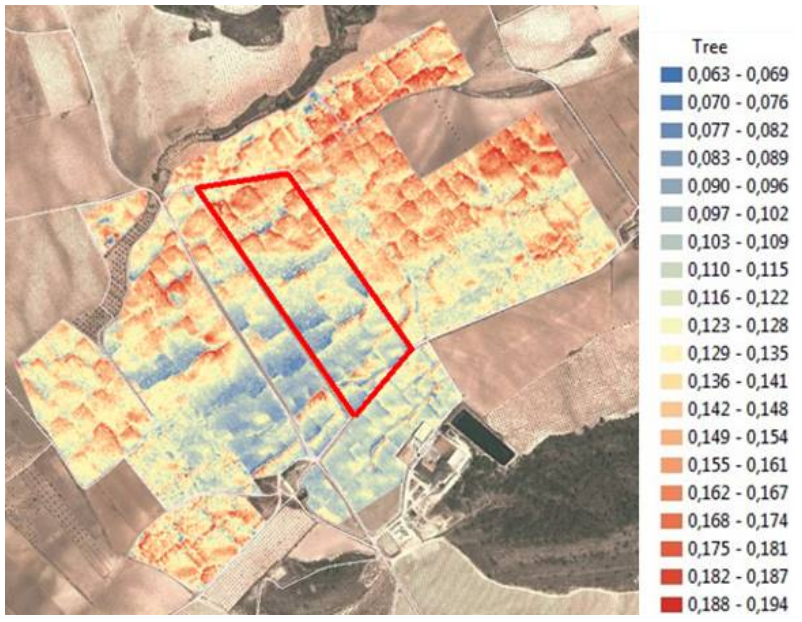

Figure 12. PRI index 2015/06/26T1330Z (0.5 m) 


\subsection{Satellites}

4.3.1 Sentinel 2A-MSI: 2015/07/6: T1103Z (10m), one image without clouds is available. In the preliminary results with bands 2, 3, 4, and 8 of the MSI sensor, four distinct areas attending to the geological origin of the plot can be distinguished in Figure 13.

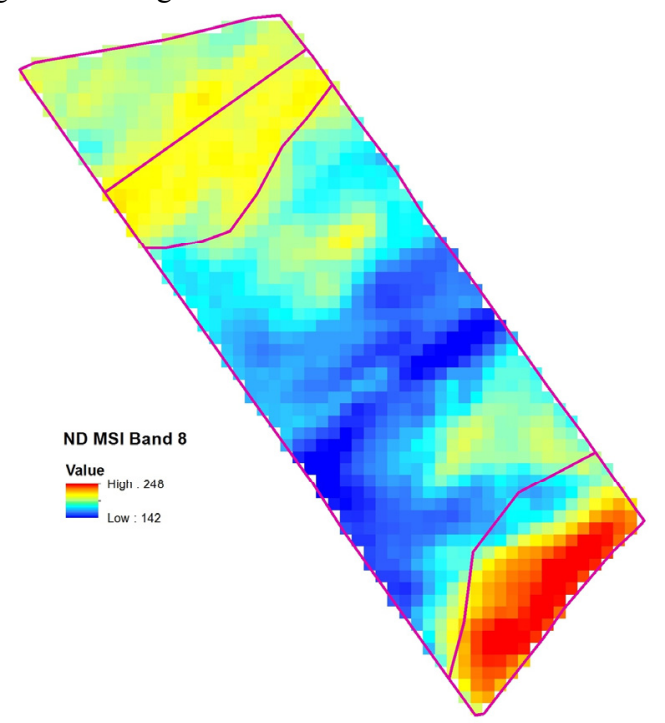

Figure 13. SII-MSI B8 2015/07/6:T1103Z (10 m).

4.3.2. Landsat 8-OLI Products: The NDVI was calculated for all available dates and plot levels, for this initial study 06.05.2015 to 11.09.2015 - and nine images without clouds are available.

Using the NDVI/SAVI OLI based on the sensor, good characterization of the plot is also achieved and the lower spatial resolution is compensated by the higher frequency of the index (Figures 14 and 15).

Conversion of the digital levels of radiance, brightness, and temperature was performed using the methodology proposed by (Chander et al., 2009). Using TIRS band 10, the four parcel, differentiated by the geological origin of the plot, can be distinguished Figure 16).

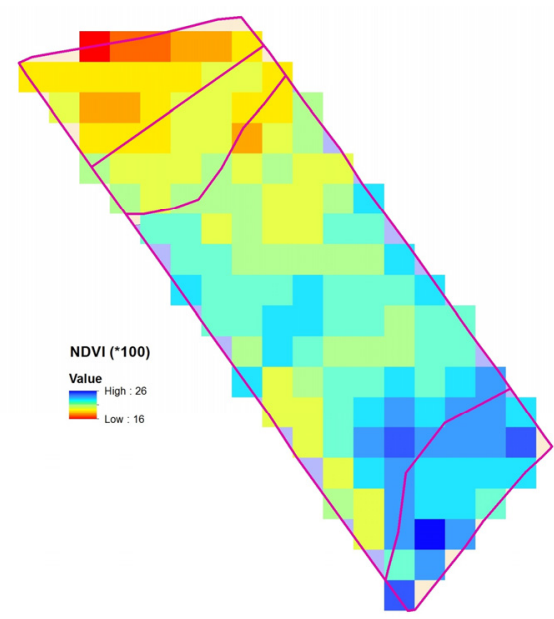

Figure 14. NDVI L8-OLI 2015/07/09:T1725Z (30 m).

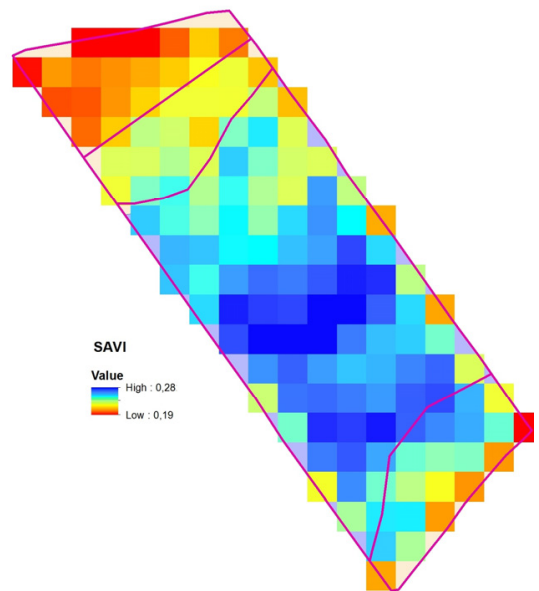

Figure 15. SAVI L8-OLI 2015/06/23:T1725Z (30 m).

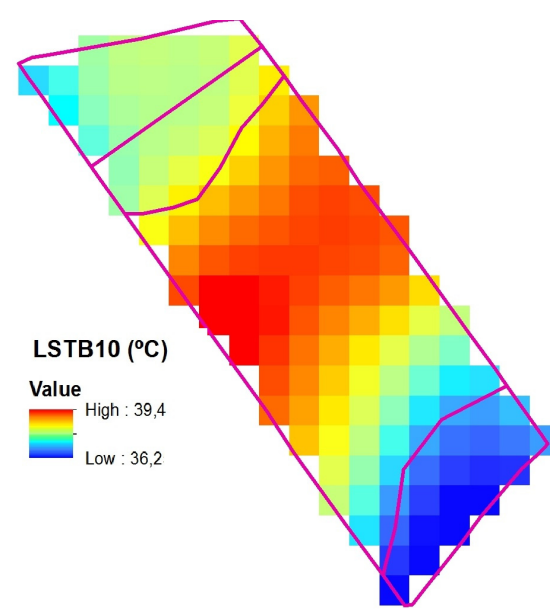

Figure 16. LSTB10 $\left({ }^{\circ} \mathrm{C}\right)$ L8-OLI 2015/07/09:T1725Z (30 m)

\subsection{Recommendations for UAV design}

The wide range of affordable UAV hardware and software now available provides the opportunity to acquire high resolution aerial photographic and video imagery of vineyards. The results demonstrate that even simple approaches can lead to the detection of slightly different canopy management methods which have an impact on yield and quality. Thus, the use of UAV-based imagery for small and fragmented vineyards has potential for vineyard managers, especially in wine regions of difficult access (Primicerio et al., 2013) and (Norzahari et al., 2011).

This UAV platform is proposed as a tool that can meet the needs of precision viticulture in terms of remote sensing, being distinguished by the low cost, timeliness, and flexibility of the measurements, customization of the equipment, full automation of the flight plan, and high precision quality of the data acquired. The UAV system developed by DRONING is a lowcost solution that is open source and fully customizable.

The tests performed show that the UAV platform may provide a tool that can be implemented at the farm level, even for small businesses (Montesinos, 2015).

For future research, the development of advanced UAV systems with thermal and spectral cameras (Flir-Tau 2/Tetracam miniMCA) would allow water stress to be monitored plant by plant. 


\subsection{UAV flight specifications}

Regarding the existing studies on the application of UAVs to plant monitoring, the UAV flight must be configured to achieve an optimal spatial resolution between 20 and $50 \mathrm{~cm}$, adequate for precision viticulture (Primicerio et al., 2013).

The UAV must be able to carry the payload of the camera and to cover the area of interest in a short time (about 30-45 min), to avoid changes in atmospheric and illumination conditions (Torres-Sánchez et al., 2013).

\subsection{Camera specifications}

To calculate the indicators required for successful detection of water stress with this state of the art technology, the UAV should carry a sensor with thermal bands. Some of the indicators, like NDVI, could be calculated when using just a multispectral camera with appropriate bands. To calculate the normalized canopy temperature, a thermal camera is required.

\section{CONCLUSIONS}

The understanding of the intra-vineyard variability is a keystone to implement effective precision agriculture practices, especially in Mediterranean environments where the land-use patterns are highly fragmented and vineyards present high heterogeneity because of variability in the soil, morphology, and microclimate. Our study, based on the comparison of different remote sensing platforms, shows that different resolutions provide similar results in the case of vineyards characterized by pronounced vegetation gradients and large vegetation clusters. On the contrary, in vineyards characterized by low vegetation gradients and high vegetation patchiness, low-resolution images fail to represent intra-vineyard variability and its patterns. Furthermore, considering the peculiarity of the crop structure of vineyards, our work points out the impossibility of distinguishing the canopy and inter-rows in the case of low-resolution images. The cost analysis shows that, beyond technical aspects, an economic break-even between UAV and the other platforms exists between 1 and 30 ha of area coverage, and that aircraft remote sensing remains competitive with satellites above this threshold.

Using the periodic satellite images of Landsat 8 and Sentinel II and the higher-resolution images obtained with UAVs, the following can be achieved in precision viticulture:

- Identification and calculation of the spatial variability in crop plots.

- Subdivision of the plots into homogeneous units for agricultural management.

- Implementation of criteria for selective harvesting, according to the quality parameters of the grapes in each homogeneous management area.

- Establishment of sampling points in the field, taking into account the variability of the crop to increase the representativeness of the sample.

\section{ACKNOWLEDGEMENTS}

This work was done with the financial support of the research project FEDER 14-20-15 (Design and implementation of spatial data infrastructure on agriculture and water in the Murcia
Region-IDEaRM), 80\% co-funded by the European Regional Development Fund (ERDF). The authors are grateful to Bodegas Juan Gil \& Gil Family Estates for hosting the experimentation.

\section{REFERENCES}

Agisoft, L. L. C. (2016). AgiSoft PhotoScan User Manual. Professional Edition, Version 1.2 (accessed 16.03.2016.). http://www.agisoft.com/pdf/photoscan-pro_1_2_en.pdf

Ariza Alexander. (2013). Descripción y Corrección de Productos Landsat 8 LDCM (Landsat Data Continuity Mission). Centro de Investigación y Desarrollo en Información Geográfica del IGAC-CIAF, 46.

Arnó Satorra, J. (2008). Variabilidad intraparcelaria en Viña: El Uso de Sensores Láser en viticultura de precisión. Universitat de Lleida. Escola Tècnica Superior d'Enginyeria Agrària.

Bellvert, J., Zarco-Tejada, P. J., Girona, J., \& Fereres, E. (2014). Mapping crop water stress index in a Pinot-noir vineyard: Comparing ground measurements with thermal remote sensing imagery from an unmanned aerial vehicle. Precision Agriculture, 15(4), 361-376. http://doi.org/10.1007/s11119-013-9334-5

Bellvert, J. (2014). El uso de la teledetección de alta resolución como herramienta para realizar un manejo eficiente del riego en viñedos. Tesis Doctoral Universidad de Córdoba.

Berni, J. A. J., Zarco-Tejada, P. J., Suárez, L., González-Dugo, $V$., \& Fereres, E. (2009). Remote sensing of vegetation from UAV platforms using lightweight multispectral and thermal imaging sensors. Int. Arch. Photogramm. Remote Sens. Spatial Inform. Sci, 38, 6 pp. http://doi.org/10.1007/s11032-006-90225 .

Chander, G., Markham, B. L., \& Helder, D. L. (2009). Summary of current radiometric calibration coefficients for Landsat MSS, TM, ETM+, and EO-1 ALI sensors. Remote Sensing of Environment, (5), 893-903.

doi:10.1016/j.rse.2009.01.007

Dobrowski, S., Pushnik, J., Zarcotejada, P., \& Ustin, S. (2005). Simple reflectance indices track heat and water stress-induced changes in steady-state chlorophyll fluorescence at the canopy scale. Remote Sensing of Environment, 97(3), 403-414. http://doi.org/10.1016/j.rse.2005.05.006

Erena, M., \& García, S. (2014). Diseño y puesta en marcha de una Infraestructura de Datos Espacial sobre Agricultura y Agua. Proceedings of the 3th Workshop on agri-food research. University Polytechnic of Cartagena. Retrieved from http://repositorio.upct.es/

Erena, M., Sánchez, D., Pecci J., Lendrino, G., Hernández Z. \& Garcia, S. (2015) Processing of satellite images. Proceedings of the 4th Workshop on agri-food research. University Polytechnic of Cartagena. Retrieved from

http://repositorio.upct.es/handle/10317/5290

ESA. (2015). SENTINEL-2 User Handbook, (1), 1-64. Retrieved from

https://sentinel.esa.int/documents/247904/685211/Sentinel-

2_User_Handbook. 
FLIR. (n.d.). Quark LWIR Camera Cores I FLIR Systems. Retrieved March 6, 2016, from

http://www.flir.com/cvs/cores/view/?id=51266

Gamon, J. A., Peñuelas, J., \& Field, C. B. (1992). A narrowwaveband spectral index that tracks diurnal changes in photosynthetic efficiency. Remote Sensing of Environment, 41(1), 35-44. Ht

Huete, A., (1988). A soil-adjusted vegetation index (SAVI). Remote Sensing of Environment, 25(3), 295-309. http://doi.org/10.1016/0034-4257(88)90106-X

Jackson, R. D., Reginato, R. J., \& Idso, S. B. (1977). Wheat canopy temperature: A practical tool for evaluating water requirements. Water Resources Research, 13(3), 651-656.

Matese, A., Primicerio, J., Di Gennaro, F., Fiorillo, E., Vaccari, F. P., \& Genesio, L. (2013). Development and application of an autonomous and flexible unmanned aerial vehicle for precision viticulture. Acta Horticulturae, 978, 6369. http://doi.org/10.17660/ActaHortic.2013.978.5

Matese, A., \& Di Gennaro, S. F. (2015). Technology in precision viticulture: A state of the art review. International Journal of Wine Research, 7(1), 69-81.

http://doi.org/10.2147/IJWR.S69405

Matese, A., Toscano, P., Di Gennaro, S. F., Genesio, L., Vaccari, F. P., Primicerio, J., Gioli, B. (2015). Intercomparison of UAV, aircraft and satellite remote sensing platforms for precision viticulture. Remote Sensing, 7(3), 2971-2990. http://doi.org/10.3390/rs70302971

Matsushita, B., Yang, W., Chen, J., Onda, Y., \& Qiu, G. (2007). Sensitivity of the Enhanced Vegetation Index (EVI) and Normalized Difference Vegetation Index (NDVI) to Topographic Effects: A Case Study in High-density Cypress Forest. Sensors, 7(11), 2636-2651.

http://doi.org/10.3390/s7112636

Montesinos, S. (2015). Aplicaciones en Agricultura. In Dirección General de Industria, Energía y Minas de la Comunidad de Madrid (eds). Los drones y sus aplicaciones en ingeniería civil:101-117.

Nebiker, S., Annen, a, Scherrer, M., \& Oesch, D. (2008). A light-weight multispectral sensor for micro UAV-opportunities for very high resolution airborne remote sensing. The International Archives of the Photogrammetry, Remote Sensing and Spatial Information Sciences, 37, 1193-2000.

Norzahari, F., Fairlie, K., White, A., Leach, M., Whitty, M., Cossell, S., Katupitiya, J. (2011). Spatially Smart Wine Testing Geospatial Technologies for Sustainable Wine Production. Civil Engineering Surveyor, (July 2011), 1-20. Retrieved from http://www.fig.net/pub/fig2011/techprog.htm

Pierce, F. J., \& Nowak, P. (1999). Aspects of Precision Agriculture. Advances in Agronomy, 67(C), 1-85. http://doi.org/10.1016/S0065-2113(08)60513-1

Primicerio, J., Matese, A., Gennaro, S. F. Di, Albanese, L., Guidoni, S., \& Gay, P. (2013). Development of an integrated, low-cost and open-source system for precision viticulture : from
UAV to WSN. In Commission of Agricultural and Biosystems Engineering (Ed.), EFITA-WCCA-CIGR Conference "Sustainable Agriculture through ICT Innovation" Turin, Italy (pp. 24-27). Torino.

Public Lab: Superblue. (n.d.). Retrieved March 12, 2016, from https://publiclab.org/notes/cfastie/04-20-2013/superblue.

QGIS. (2016). Guia de usuario de QGIS. Retrieved March 22, 2016, from http://docs.qgis.org/2.8/es/docs/user_manual/

Reuter, H. I., \& Kersebaum, K. C. (2009). Applications in precision agriculture. Developments in Soil Science (Vol. 33). http://doi.org/10.1016/S0166-2481(08)00027-5

Rouse, J. W. J. (1972). Monitoring the vernal advancement and retrogradation (green wave effect) of natural vegetation. Retrieved from

http://ntrs.nasa.gov/search.jsp? $R=19730009607$

Suarez, L., Zarco-Tejada, P. J., Gonzalez-Dugo, V., Berni, J. A. J., Sagardoy, R., Morales, F., \& Fereres, E. (2010). Detecting water stress effects on fruit quality in orchards with time-series PRI airborne imagery. Remote Sensing of Environment, 114(2), 286-298. http://doi.org/10.1016/j.rse.2009.09.006

Tanner, C. B. (1963). Plant Temperatures1. Agronomy Journal, 55(2), 210.

http://doi.org/10.2134/agronj1963.00021962005500020043x

Tetracam. (2016). Tetracam Micro-MCA. Retrieved February 25 , 2016, from http://www.tetracam.com/ProductsMicro_MCA.htm

Thenot, F., Méthy, M., \& Winkel, T. (2010). The Photochemical Reflectance Index (PRI) as a water-stress index. International Journal of Remote Sensing. Retrieved from http://www.tandfonline.com/doi/abs/10.1080/014311602101631 00

Torres-Sánchez, J., López-Granados, F., De Castro, A. I., \& Peña-Barragán, J. M. (2013). Configuration and specifications of an Unmanned Aerial Vehicle (UAV) for early site specific weed management. PloS One, 8(3), e58210. http://doi.org/10.1371/journal.pone.0058210

USGS. (2015). Landsat 8 (L8) Data Users Handbook. Earth Resources Observation and Science (EROS) Center, Retrieved June 8, 2015. from

http://landsat.usgs.gov/documents/Landsat8DataUsersHandboo k.pdf 